\title{
Extra Pulmonary Tuberculosis in Body Fluids
}

\author{
K. Ruckmani, A. Shanthi*, P. Shanmugapriya and Eunice Swarna Jacob \\ Department of Microbiology, Thanjavur Medical College, Thanjavur, Tamil Nadu, India \\ *Corresponding author
}

\begin{tabular}{|c|}
\hline Keywords \\
\hline $\begin{array}{l}\text { Extra pulmonary } \\
\text { Tuberculosis, } \\
\text { Pleural Fluid, } \\
\text { Ascitic Fluid, } \\
\text { Pericardial Fluid, } \\
\text { Cerebro spinal } \\
\text { Fluid }\end{array}$ \\
\hline Article Info \\
\hline $\begin{array}{l}\text { Accepted: } \\
\text { 12 June } 2021 \\
\text { Available Online: } \\
10 \text { July } 2021\end{array}$ \\
\hline
\end{tabular}

A B S T R A C T

Extra Pulmonary Tuberculosis is defined as any bacteriologically confirmed or clinically diagnosed case of Tuberculosis involving organs other than the lungs. It is usually, both diagnostic and therapeutic challenge with available data. The aim of this study is to assess the incidence of bacteriologically confirmed cases of extra Pulmonary Tuberculosis and to determine the most affected organs and to assess the most common presentation of extra pulmonary tuberculosis in body fluids. Pulmonary tuberculosis is the most important public health challenge in the developing countries. Extra pulmonary tuberculosis is still more challenging. The worst human health scenarioin $3^{\text {rd }}$ world's nation is Extra Pulmonary Tuberculosis with co-infection with human immuno deficiency virus (HIV) and malnutrition is a further aggravating factor. Objective of the study is to explore the magnitude of extra pulmonary Tuberculosis and to assess the challenge faced in encountering the patient with malnutrition, HIV infection etc. This study is a Prospective study in Thanjavur medical college, central diagnostic laboratory in Department of Microbiology combined with Department of Medicine and Department of Thoracic medicine in Thanjavur medical college during the Period of January 2020 to December 2020. Even though high incidence of Extra Pulmonary Tuberculosis is encounter in poor socio-economic status, rural back ground and people living with HIV and AIDS, upper and middle classes are not exempted from the diagnostic and therapeutic challenges. Despite excellent treatment of Tuberculosis, outcomes in this setting, the proportion of cases with susceptibility data is worrying in this era of increasing drug resistance, and illustrates the diagnostic difficulties faced even in a well-resourced setting. The percentage of Extra Pulmonary Tuberculosis cases in body fluids in this study is $10 \%$.

\section{Introduction}

The incidence of the tuberculosis is estimated that two billion of the world's population is infected with the tubercle bacilli. Every year between eight and nine million of
Tuberculosis appear, and three million people die from the disease Majority of the cases and deaths are from poor nations. India is one of the worst affected countries. More than forty percent of the population is infected and around 15 million suffer from tuberculosis. 
Over three million cases are highly infectious, Open cases, Half a million people die from the tuberculosis every year in India, one person per minute.

During the Late 1980 and 1990s, the number of reported cases of tuberculosis increases in industrialized countries. This increase were related largely to immigration from countries with high incidence of Tuberculosis; The spread of the HIV epidemic, social problems such as increased urban poverty, Homelessness, and Drug abuse, and Dismantling of Tuberculosis services

More than 5.7 million new cases of Tuberculosis(all forms both pulmonary and extra pulmonary were reported to the World Health Organization in 2013, 95\% of the cases were reported from developing countries. However because of insufficient case detection and incomplete notification, reported cases may represent only about two thirds of the total estimated cases.

During the past few years, numbers of reported cases have begun to decline again, all have stabilized in most industrialized nations. In the United States, with the re-establishment of stronger control programs, the decline resumed in 1993 and has since been maintained, In 2013, 9582 cases of Tuberculosis have been reported to the Centers for Disease Control and Prevention (CDC).

Tuberculosis (TB) is a leading cause of morbidity and mortality worldwide, accounting for about 9.6 million new cases and 1.5 million deaths annually.

Tuberculosis is a double edged sword which causes socioeconomic burden apart from disease burden. It affects the economically and intellectually productive age groups mainly the males of the society.
Globally, tuberculosis (TB) is among the top five killers of women aged 20-59 years. While the proportion of pulmonary TB (PTB) notifications is higher among males worldwide, TB in females remains a major threat to control due to the impact felt by households, particularly children. It has been argued that the higher case notifications among males are common. Tuberculosis remains a major global health problem with most of world's population and being infected with tuberculosis co-infection with HIV, Diabetes mellitus and recently evolved drug resistant tuberculosis and it is a big threat for mankind.

Poverty and tuberculosis go hand in hand, tuberculosis has declined rapidly in the affluent nations due to improvement in the standard of living but continues unabated in the poorer countries. Currently with AIDS Pandemic, tuberculosis become a problem for developed nations as well, with outbreaks among the HIV- Infected individuals. A close relationship has emerged between tuberculosis and HIV. Not only does HIV infection reactivate latent tuberculosis but it also makes the disease more serious and renders treatment ineffective. Tuberculosis may, in turn, hasten the development of HIV infection into active disease.

TB can involve any organ in the human body. Where PTB is the most common presentation, Extra Pulmonary Tuberculosis is also an important clinical problem. The term EPTB is used to describe the TB at any body sites other than the lungs. Diagnosis of Extra Pulmonary Tuberculosis is done by Ziehl-Neelsen stain in this study. Lack of diagnostic tests for procurement of tissue or fluid from an accessible sites and a poor yield of conventional diagnostic methods leads to a considerable delay in the time or diagnosis may be missed. Due to the availability of sophisticated investigations like CT, 
endoscopy, MRI, have tremendously helped in localization of anatomical site. For obtaining tissue diagnosis histo-pathological examination is done.

Extra pulmonary tuberculosis (EPTB) Accounted For $15 \%$ of the new and relapse TB cases in 2014.

The percentage of Extra Pulmonary Tuberculosis among all TB cases in developed countries ranges from 12 to $28.5 \%$. In developing countries like India, The percentage of EPTB cases is between $15-20 \%$ which has increased to more than 50\% among HIV co infected patients suggesting immune status of the host being a major risk factor of Extra Pulmonary Tuberculosis.

Pulmonary TB represents about $70 \%$ of all cases of TB and is the most infectious form of $\mathrm{TB}$ and remains the major target for $\mathrm{TB}$ control.

Extra-pulmonary tuberculosis (EPTB) defined as any bacteriologically confirmed or clinically diagnosed case of TB involving organs other than the lungs. The description of a form of Extra Pulmonary Tuberculosisis a location affecting the pleura, lymph nodes, abdomen, genitourinary tract, skin, joints and bones, meninges and it's function.

Extra Pulmonary Tuberculosis represents 15 to $30 \%$ of all forms of tuberculosis and is frequently a diagnostic and therapeutic challenge. It is a common opportunistic infection in people living with HIV/AIDS and other immunocompromised states.

The immunocompromised status of these persons results in dissemination of the bacteria form the lungs to other organs. There is a paucity of data on bacteriological diagnosis and therapeutic evaluation on Extra Pulmonary Tuberculosis.
The aim and objective of this study is to assess the incidence of bacteriologically confirmed EPTB during the study period January 2020 to December 2020 and also to classify Extra Pulmonary Tuberculosis patients in relation to different body fluids of involvement and to correlate them in relation to the epidemiological factors like age, sex and also to study the correlation with HIV and diabetes mellitus the most important risk factor influencing Extra Pulmonary Tuberculosis.

\section{Materials and Methods}

The study is Prospective, record based study done to analyze patients of Extra Pulmonary Tuberculosis. Study was conducted in the department of microbiology combined with department medicine and department of thoracic medicine patients in ward, During the period of January 2020 to December 2020.

\section{Inclusion criteria}

Extra pulmonary tuberculosis cases in body fluids.

\section{Exclusion criteria}

Pulmonary tuberculosis cases.

\section{Materials and Methods}

The study was included all in patients in department medicine and department of thoracic medicine, Who were suspected to be suffering from Extra Pulmonary Tuberculosis during the study period. The diagnosis of Extra Pulmonary Tuberculosis was established with lab diagnosis.

\section{Clinical Spectrum}

The site of lesion of Extra Pulmonary Tuberculosis. 


\section{Demographic Data}

The age and sex distribution of Extra Pulmonary Tuberculosis.

\section{Incidence}

It is defined as number of NEW CASES occurring in a defined population during a specified period of time. In this study the number of New cases of Extra Pulmonary Tuberculosis reported in this center during the period January 2020 to December 2020.

\section{Sampling}

All patients diagnosed to have Extra Pulmonary Tuberculosis during the year January 2020 to December 2020 satisfying the inclusion criteria was included into the study.

\section{Sample Size}

All samples (body fluids) are sent to microbiology laboratory for diagnosis of Extra Pulmonary Tuberculosis during the period January 2020 to December 2020. Total no samples are 276.

\section{Data analysis}

All data were entered into Microsoft excel and was analyzed using Microsoft Excel sheet and Microsoft Word. They were represented as charts, table and graphs to reach to interpretations.

\section{Results and Discussion}

Total Number of tested samples are 276. Among 276 positive number of samples in Ziehl-Neelsen stain are 27. In age wise distribution 0-10 years 3 samples are positive. In 11-20 years 2 samples are positive. In 2130 years 4 samples are positive. In 31-40 years 3 samples are positive. In 41-50 years 9 samples are positive. In 51-60 years 4 samples are positive. In 61-70 years 2 samples are positive.

\section{Sex wise distribution of extra pulmonary tuberculosis}

Total Number of tested samples are 276. Among 276 positive number of samples in Ziehl-Neelsen stain are 27. Among 27 positive samples 15 are Males. In 27 positive samples 12 are Females.

\section{Anatomical distribution of extra pulmonary tuberculosis}

Total Number of tested samples are 276. Among 276 positive number of samples in Ziehl-Neelsen stain are 27. Among 27 positive samples 10 are Ascitic Fluid. Among 27 positive samples 8 are Pleural Fluid. Among 27 positive samples 8 are Cerebrospinal Fluid.

\section{Distribution of rare site of involvement of extra pulmonary tuberculosis}

Total Number of tested samples are 276. Among 276 positive number of samples in Ziehl - Neelsen stain are 27. Among 27 Positive samples Pericardial Fluid is 1 . It is a very rare involvement of Extra Pulmonary Tuberculosis.

\section{Fluorescent microscopy}

In 27 Ziehl-Neelsen stain positive sample 2 samples are positive for Fluorescent stain (Auramine - Rhodamine stain) also.

\section{CBNAAT}

In 27 Ziehl-Neelsen stain positive sample 1 sample is positive for CBNAAT in CEREBROSPINAL FLUID.

Histopathology 
In 27 Ziehl-Neelsen stain positive sample for 3 patients histopathological findings also positive for Tuberculosis.

\section{Adenosine deaminase assay}

In 27 Ziehl-Neelsen stain positive sample for 2 patients Adenosine deaminase is elevated.

Extra Pulmonary Tuberculosis Is a major public health issue which has a greater diagnostic challenge.

$10 \%-15 \%$ of the total Tuberculosis cases are extra Pulmonary Tuberculosis. Extra Pulmonary Tuberculosis has been exhaustively studied in literature with a varied range of clinical reports/case series of microbiologically confirmed cases of Extra Pulmonary Tuberculosis.

Socio-economic factor like malnutrition, poverty and tuberculosis are both problems of considerable magnitude in India. It is important to consider, how these problems tend to interact with each other.

The link between tuberculosis and malnutrition has long been recognized; malnutrition may predisposed people to the development of clinical disease and tuberculosis can contribute to malnutrition. The direct evidence of effect of nutrition on tuberculosis is difficult because of whole complex of coincidence and environmental factors, the less the weight of patient evidence still favors the view that malnutrition may be an important factor in the high mortality and morbidity from tuberculosis, three important questions are. Does malnutrition predispose to tuberculosis infection in poor socio economic status people? Does malnutrition influence or modify the course and establishment of the tuberculosis infection? Do nutritional factors influence their response to treatment?

Substantial experimental evidence suggests that malnutrition can lead to secondary immuno deficiency that increases the host susceptibility to infection. Increased risk of tuberculosis can result from alteration in the individual protective function of lymphocytes and macrophages because of nutritional insult. Thus nutritional supplementation may represent a novel approach for recovery in tuberculosis patients. Improving nutritional status of population may prove to be an effective measure to control tuberculosis in developing nation.

Overcrowding slum, migration of labour, homelessness, drug abused, alcoholic and smoker are equally linked to HIV and TB. TB \& HIV act in deadly synergy. HIV infection increase the risk exposure to $\mathrm{TB}$, progression of latent to active and death if HIV are not treated timely manner.

Contrary to the previous belief "TB being a poor man disease", more and more Extra Pulmonary Tuberculosis are notified in high socio economic status people. It affects people across all socioeconomic status, no group is exempted. Logically HIV is common amongst high socio economic people and TB is common infection in People PLWHA. Thus TB can affect middle and upper class as well.

If the immune system is not impaired, a person infected in tubercular bacillus has $10 \%$ risk during their life time of developing activities. The co-infection with HIV\& TB possesses numerous risks, $10 \%$ risk per year of contracting Tuberculosis. HIV epidemic has been main reason for resurgence of the Extra Pulmonary Tuberculosis. Expose to Tuberculosis is in evitable in the developing nation. But natural immunity keeps the person resistant to tuberculosis. 
Table. 1 Tests done in this center

\begin{tabular}{|c|c|c|c|}
\hline $\begin{array}{l}\text { Diagnostic } \\
\text { Method }\end{array}$ & $\begin{array}{l}\text { Sensitivity/ } \\
\text { specificity }\end{array}$ & Advantages & Limitations \\
\hline \multicolumn{4}{|c|}{ Direct Methods } \\
\hline $\begin{array}{l}\text { ZiehlNeelsen } \\
\text { stain }\end{array}$ & $\begin{array}{c}\text { Very } \\
\text { low/high }\end{array}$ & $\begin{array}{l}\text { Simple, cheap, rapid, } \\
\text { grading of disease }\end{array}$ & $\begin{array}{l}\text { No species, viable bacteria \& } \\
\text { drug susceptibility detection }\end{array}$ \\
\hline $\begin{array}{l}\text { Fluorescent } \\
\text { microscopy }\end{array}$ & low/high & $\begin{array}{c}\text { Slightly better } \\
\text { sensitivity than Ziehl- } \\
\text { Neelsen stain }\end{array}$ & $\begin{array}{l}\text { Expensive \& complex, no } \\
\text { species, viable bacteria \& drug } \\
\text { susceptibility detection }\end{array}$ \\
\hline CBNAAT & High/high & $\begin{array}{l}\text { Rapid, automated, } \\
\text { drug susceptibility }\end{array}$ & $\begin{array}{c}\text { Low sensitivity } \\
\text { inculturenegative EPTB, } \\
\text { expensive, cannot identify } \\
\text { viable bacteria }\end{array}$ \\
\hline \multicolumn{4}{|c|}{ Indirect Methods } \\
\hline Histopathology & High/low & Differential diagnosis & $\begin{array}{l}\text { Invasive, atypical lesion in } \\
\text { HIV, required surgical } \\
\text { facility, sinus tract \& fistula } \\
\text { formation }\end{array}$ \\
\hline $\begin{array}{c}\text { Adenosine } \\
\text { deaminase assay }\end{array}$ & High/low & $\begin{array}{c}\text { Simple, less } \\
\text { expensive, rapid }\end{array}$ & Specificity need evaluation \\
\hline
\end{tabular}

Table.2 Age wise distribution in of Extra Pulmonary Tuberculosis detected in Body fluids

\begin{tabular}{|c|c|c|}
\hline AGE IN YEARS & $\begin{array}{c}\text { NUMBER OF } \\
\text { POSITIVE SAMPLE }\end{array}$ & PERCENTAGE \\
\hline $\mathbf{0 - 1 0}$ & 3 & $11.5 \%$ \\
\hline $\mathbf{1 1 - 2 0}$ & 2 & $7 \%$ \\
\hline $\mathbf{2 1 - 3 0}$ & 4 & $15 \%$ \\
\hline $\mathbf{3 1 - 4 0}$ & 3 & $11.5 \%$ \\
\hline $\mathbf{4 1 - 5 0}$ & 9 & $33 \%$ \\
\hline $\mathbf{5 1 - 6 0}$ & 4 & $15 \%$ \\
\hline $\mathbf{6 1 - 7 0}$ & 2 & $7 \%$ \\
\hline TOTAL & $\mathbf{2 7}$ & $\mathbf{1 0 0} \%$ \\
\hline
\end{tabular}

Table.3 Sex wise Distribution of Extra pulmonary Tuberculosis:

\begin{tabular}{|c|c|c|}
\hline SEX & $\begin{array}{c}\text { NUMBER POSITIVE } \\
\text { SAMPLE }\end{array}$ & PERCENTAGE \\
\hline Male & 15 & $55 \%$ \\
\hline Female & 12 & $45 \%$ \\
\hline Total & $\mathbf{2 7}$ & $\mathbf{1 0 0} \%$ \\
\hline
\end{tabular}


Table.4 Distribution of positive samples in body fluids

\begin{tabular}{|c|c|c|c|}
\hline Specimen & $\begin{array}{c}\text { Number of } \\
\text { Sample tested }\end{array}$ & $\begin{array}{c}\text { Number of Positive } \\
\text { sample }\end{array}$ & Percentage \\
\hline Ascitic Fluid & 104 & 10 & $38 \%$ \\
\hline Pericardial Fluid & 10 & 1 & $4 \%$ \\
\hline Pleural Fluid & 137 & 8 & $29 \%$ \\
\hline $\begin{array}{c}\text { Cerebrospinal } \\
\text { Fluid }\end{array}$ & 25 & 8 & $29 \%$ \\
\hline Total & $\mathbf{2 7 6}$ & $\mathbf{2 7}$ & $\mathbf{1 0 0} \%$ \\
\hline
\end{tabular}

Fig.1

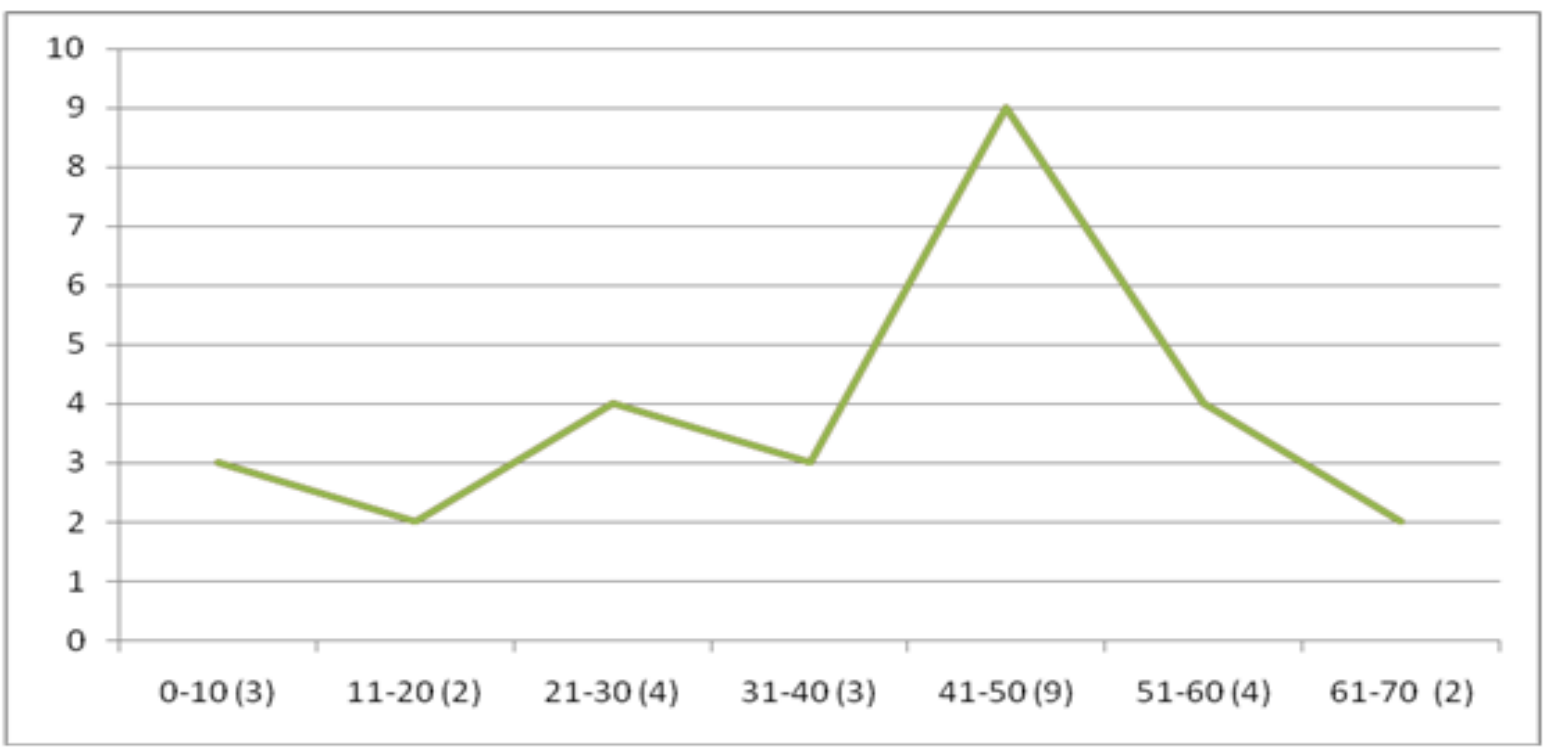

Fig.2

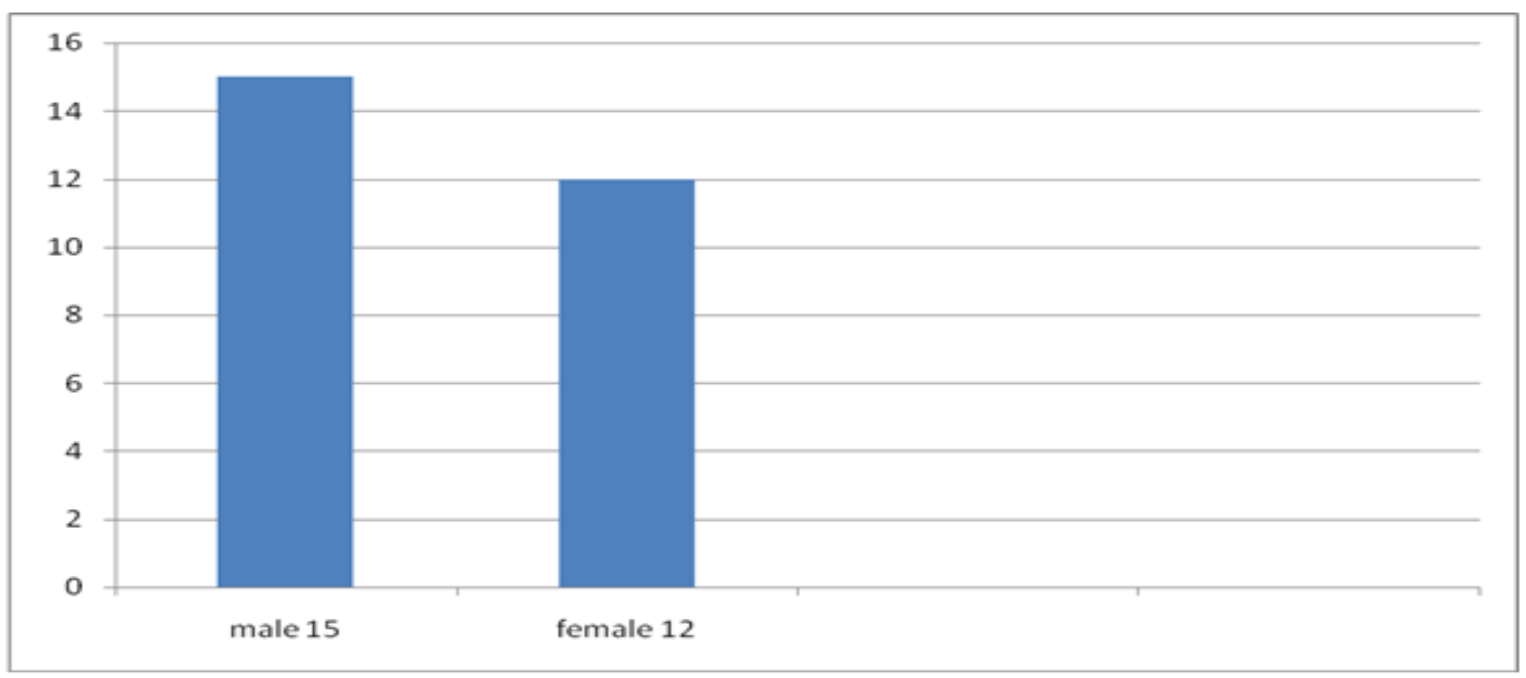


Fig.3

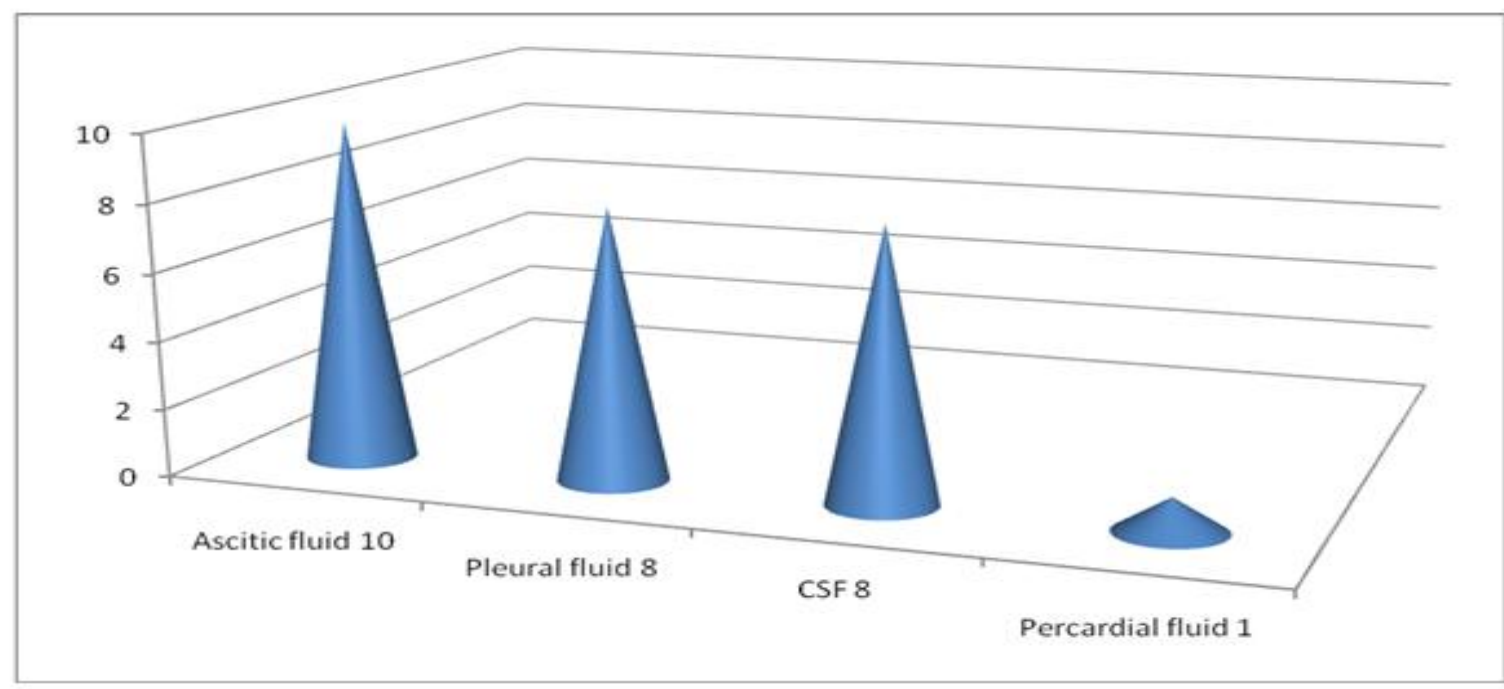

But often factors like the modern work culture, stressful work erratic life style weakened the immune and trigger disease, accounting for such high prevalence of Extra Pulmonary Tuberculosis in high socio economic status people groups.

Importantly, we reveal the extent of diagnostic challenges even in a well-resourced setting, with only approximately half of cases being microbiologically confirmed.

In this study Percentage of Positive rate for Extra Pulmonary tuberculosis in body fluid is $10 \%$. This study is correlated with the study of Resurgence of Extra Pulmonary Tuberculosis by Dr. S. Bag.

In age wise distribution $0-10$ years 3 samples are positive. In 11-20 years 2 samples are positive. In 21-30 years 4 samples are positive. In 31-40 years 3 samples are positive. In 41-50 years 9 samples are positive.In51-60 year 4 samples are positive. In 61-70 years 2 samples are positive. In this study the highest incidence occurs in between the age group 41-50. Total Number of tested samples are 276. Among 276 positive number of samples in Ziehl-Neelsen stain are 27. Among 27 positive samples 15 are Males. In 27 positive samples 12 are Females. In this study highest incidence of Extra Pulmonary tuberculosis occurs in Males.

The Percentage of Ascitic Fluid in Positive Samples is $38 \%$. Extra pulmonary tuberculosis in body fluids has high incidence in ascitic fluid. The Percentage of Pericardial Fluid in Positive Samples is 4\%. The Percentage of Pleural Fluid in Positive Samples is 29\%.The Percentage of Cerebrospinal Fluid in Positive Samples is $29 \%$, So it is important to rule out Tuberculous meningitis in all meningitis Patients.

In this study all samples screened by ZiehlNeelsen stain. For 2 samples Ziehl-Neelsen stain and fluorescent stain are Positive.

CBNAAT and Ziehl-Neelsen stain is Positive in 1 sample in Tuberculous meningitis.

Adenosine deaminase is elevated in 2 samples in 27 Positive Samples. In 27 Positive Samples 10 Patients haveHIV.8 Patients have 
diabetes mellitus. 6 Patients have High blood pressure.

In 27 Positive Samples 25 Patients are in below poverty line.

Like PTB, Extra Pulmonary Tuberculosis also remains a major health problem and carries an important role in epidemiology of Tuberculosis. Extra Pulmonary Tuberculosis involves economically poor status people and sexually reproductive age group, thus affecting the economy of the country. Therefore all the efforts should be directed towards early and prompt diagnosis of such cases with the help of newer diagnostic tests which are more sensitive and specific and these facilities should be extended to the most remote and resource poor areas of the county.

Secondly large scale studies at the national program level should be conducted to formulate the strategies for expert management of such cases. In India, Revised National Tuberculosis Control Program was implemented in 1992, the aim was to provide standard treatment and diagnostic facilities.

Every diagnosed case of Tuberculosis should be subjected to HIV testing and every HIV case if symptomatic for PTB or Extra Pulmonary Tuberculosis should be screened thoroughly.

There is a need to focus on Extra Pulmonary Tuberculosis in populations to document the epidemiology in India examine the risk factors, diagnostic modalities, treatment strategies, and outcomes to carry out preventive and control measures. By improving infrastructure of the treating hospital, Lab facilities and Introduction of new diagnostic methods, The outcome will better. To stop Tuberculosis strategy of World Health Organization, To reduce the global burden of TB and TB free world in line with the millennium Development Goals and the Stop TB Partnership targets, WHO has laid out the following objectives:

Achieve universal access to high-quality care for all people with TB

Reduce the human suffering and socio economic burden associated with TB

Protect vulnerable population from TB, TB/HIV and multidrug resistant TB

Support development of new tools and enable their timely and effective use

Protect and promote human rights in TB prevention, care and control

\section{References}

Resurgence of extra pulmonary tuberculosis Bag S, Deep N, Padhy S

CLINICO - Epidemiological Profile of Extra Pulmonary Tuberculosis in Western India - Anita Velingker, Durga Lawande, Lamartine Dcosta

Extra pulmonary tuberculosis among Females in South Asia -gap analysis JaishriMehraj, Zain Yar Khan, Dania Khalid Saeed, SadiaShakoor, RuminaHasan.

Extrapulmonary drug- resistant tuberculosis at a drug- resistant tuberculosis center, Mumbai: Our experience - Hope in the midst of despair - Unnati Desai, Jyotsna M Joshi, Department of Pulmonary Medicine, T.N. Medical College, B. Y. L. Nair Hospital, Mumbai, Maharashtra, India.

Changing trends in incidence and clinical spectrum of extra-pulmonary tuberculosis: a 10-year retrospective study in a rural teaching hospital in South India - Sanoop Kumar Sherin Sabu, Vergis Paul, Deepu J. E. 
Mathew, T..Jacob, Celine T. M.

Laboratory Diagnosis of Extra - Pulmonary Tuberculosis (EPTB) in Resourceconstrained Setting: State of the Art, Challenges and the Need - Manu purohit, Tehmina Mustafa.

Bacteriologically confirmed extra pulmonary tuberculosis and treatment outcome of patients consulted and treated under program conditions in the littoral region of Cameroon - Teyim pride Mbuh, Irene Ane-Anyangwe, Wandji Adeline, Benjamin D. Thumamo Pokam, Henry Dilonga Meriki and Wilfed Fon Mbacham.

Epidemiology, Diagnosis and Management of Extra-Pulmonary Tuberculosis in a Low- Prevalence Country: A Four Year Retrospective Study in and Australian Tertiary Infectious Diseases Unit - Simon Pollett, Pamela Banner, Matthew V.N.O Sullivan, Anna P. Ralph.

Extra-Pulmonary Tuberculosis in Pakistan - A nation- wide multicenter retrospective study- Sabira Tahsen, Faisal Masood Khanzada, Aurangzaib Quadir Baloch, Qasimabbas, Mansoor Manzoor Bhutto, Ahmad waliAlizi, Shah Zaman, Zahida Qasim, Muhammad Najeeb Durrani, M. Khalid Farough, Atiqa Ambren, Nauman Safdar, Tehmina Mustafa.

Extra-Pulmonary Tuberculosis in Kabul, Afghanistan: A hospital- based retrospective review - Tim fader, John Parks, Najeeb Ullah Khan, Richard Manning, Sonya Stokes, Nasir Ahmad Nasir.

Lopez A D, Mothers C D, Ezzali M, Jamison $\mathrm{D}$ T. Global and regional burden of disease and risk factor 2001; systematic analysis of population health data lancet 2006;367:1747-57.

Mohan A, Sharma S K. Epidemiology in Sharma S K, Mohan A, (Editor)
Tuberculosis New Delhi, Jaypee Brother's Brother Medical Publisher 2001 P-14-29.

Sharma S K, Mohan A. Extra-Pulmonary Tuberculosis, Indian $\mathrm{J}$ of Med Res 2004;120:316-53.

Muriyandi M, Ramchandran R, Balasubramanian R, Narayan P R. Socio-economic dimension of Tuberculosis: Review of study over two decade from TRC.J.comn Dis 2006; 38:204-15.

Dollin P J, Raviglinone M C \& Kochi A. Global Tuberculosis and mortality during 1990-2000, Bull World Health Organization 1994;72:213-20.

World Health Organization Standards for extra pulmonary tuberculosis $2014 ; 30$ 32.

Deepiyoti V, Usha R sing, Kamlesh Sexena, rate bhatia, bibhatalwar. Diagnosis of tubercular cervical lumphadenities by FNAC, Microbiology\& Culture, Indian J Tuberculosis 1991;38:25.

Jain R, Sawhneys, Bhargava D K, Berry M. Diagnosis of Abdominal Tuberculosis: sonographic finding in patient with early disease. |Am KJ: Roentgenol 1995;165:1391-5

Freser Ware, Balasubramanian R, A. Mohan S K. Sharma. Extra-Pulmonary Tuberculosis: management and control, Tuberculosis control in India 2010;95-114.

WHO Health Organization (WHO) in standard for TB care in India - addressing TB \& HIV condition and co-morbid condition 2014;51.

S Tripathy, A Ananda, V. Inamadar. Clinical response of newly diagnosis HIV sero positive and sero negative pulmonary tuberculosis patient with RNTCP short course regiment in Pune in India/ Indian J med Research 2011;521-528.

Corbett E. L. watt C J, walker $\mathrm{N}$ et al., growing Burden of tuberculosis global 
tends and inter action with HIV epidemic |Arch Intern Med 2003;163:1009.

Sharma S K. Mohan A. Co-infection with human immune deficiency girus (HIV and Tuberculosis, Indian prospective. Indian J Tuberculosis 2004;51-16.

HIV T B in India-By Soumya Swaminathan and V. Narendra. Deptt. Of Clinical Research, TB Research Centre, India.

Rao K N, Gopalan C. The role of nutritional factors in tuberculosis, Indian $\mathbf{J}$ Tuberculosis 1966;13;102-6

Krishana Behari Gupta, Rajesh Gupta, Atulya Atreja, Manishverma, Suman V. Tuberculosis and nutrition. Lung India 2009;26:9-16.

Godfrey fausette $\mathrm{P}$ and $\mathrm{H}$. Ayles. Can we control tuberculosis in high HIV prevalence setting? Tuberculosis (Edins) 2003;83:68-76.

K. Venugopal, P R srelatha, Sairu Philip \& Vijaya Kumar. Treatment outcome of Neuro Tubercuosis Patients put on DOTS, Indian $\mathrm{J}$ of tuberculosis 2008;55:1990-2002.......

GLOBAL TUBERCULOSIS REPORT 2013, Page 6. Available at: http//a[[s.who.int/iris/bitstream/10665/ 91355/1/9789241564656_eng.pdf

Global tuberculosis control, WHOO report 2001, WHO/CDS/TB/2001.287. Communicable Diseases, World Health Organisation, Geneva 2001: pp.8-34.

Tanzania Social Sector Review, world Bank Report 1999.

Purohit M R, Mustafa T, Wiker H G, Morkve $\mathrm{O}$, Sviland L. Immunohistochemical diagnosis of abdominal and lymph node tuberculosis by detecting Mycobacterium tuberculosis complex specific antigen MPT64. DiangnPathol 2007;2:36.

Purohit M R, Mustafa T, Wiker H G, Sviland L. Rapid diagnosis of tuberculosis in aspirate, effusions, and cerebrospinal fluid by immunocytochemical detection of Mycobacterium tuberculosis complex specific antigen MPT64. Cytopathol.2012;40(9):782-91.

Menzies D. Using Tests for Latent Tuberculos infection to Diagnose Active Tuberculosis: Can We Eat Our Cake and Have It Too? Ann Intern Med. 2008; 148(5):398-99.

Davies P D Pai M. The diagnosis and misdiagnosis of tuberculosis. The international journal of tuberculosis and lung disease: the official journal of the Intenational Union against Tunerculosis and lung disease: the official journal of the international Union against Tunerculosis and Lung Disease. 2008:12(11):1226-34.

Bayazit Y A, Bayazit N, Namiduru M, Mycobacterical cervical lymphadenitis. ORL J OtorihinolaryngolRelat Spec.2004;66(5):275-80.

Global tuberculosis control.WHO report, 2009.

Garcia de Viedma D, Marin M, Ruiz Serrano M J, Alcala L, Bouza E, Polyclonal and compartmentalized infection by Mycobacterium tuberculosis in patients with both respiratory and extra respiratory involvement. JJ Infect Dias.2003: 187(4):695-99.

Daley P, Thomas, PaiM.Nuclenic acid amplification tests for the diagnosis of tuberculosis and lung disease: the official journal of the International Union against Tuberculosis and Lung disease: the official journal of the International Union against Tuberculosis and Lung Disease, 2007;11(11):1166-76.

Dinnes J, Deeks J, Kunst H, Gibson A, Cummins E, Waugh $\mathrm{N}$, et al., A systematic review of rapid diagnostic 
tests for the detection of tuberculosis infection. Health technology assessment.2007: 11(3):1-196.

Pai M, Flores L L, Hubbard A, Riley LW,Colford JM, Jr.Nucleic acid amplification tests in the diagnosis of tuberculous pleuritis: a systematic review and met analysis. BMC Infect Dis. 2004:4:6.

Pai M, Flores L L, Pai N, Hubbard A, Riley L W, Colford J M, Jr. Diagnostic accuracy of nucleic acid amplification tests for tuberculous meningitis: a systematic review and meta-analysis. The Lancet infectious diseases.2003;3(10):633-43.

Villegas M VmKabrada L A, Saravia N G. Evaluatio of poly,erase chain reaction, adenosine deaminase, and interferongamma ain pleural fluid for the differential diagnosis of pleural tuberculosis. Chest.2000:118(5):135564.

Mustafa T, Wiker $\mathrm{H}$ G, Mfinanga S G, Morkve O, Sviland L. Immunohistochemistry using a Mycobacterium tuberculosis complex specific antibody for improved diagnosis of tuberculous lymphadenitis. Mod Patholo.2006;19(12):1606-14.

Noordhoek G T, Kolk A H, Bjune G, Catty D, Dale J W, Fine P E, et al., Sensitivity and specificity of PCR for detection of Mycobacterium tuberculosis: a blind comparison study among seven laboratories. Journal of clinical microbiology.1994;32(2):277-84.

Diagnostic Standards land Classification of Tuberculosis in Adults and Children Am J RespirCritt Care Med.2000;1614(4Pt 1):1376 -95.

Lawn S D, Mwaba P, Bates M, Pitek A, Alexander H, Maais B J, et al., Advances in tuberculosis diagnostics: the Xpert MTB/RIF assay and future prospects for a point-of-care test. The Lancet infectious diseases. 2013:13(4):349-61.

Friedrich SO, von Groote-Bidlingmaier F, Diacon Ah. Xpert MTB/RIF assay for diagnosis of pleural tuberculosis. Journal of clinical microbiology. 2011;49(12):4341-42.

Vadwai V, Boehme C, Nabeta P, Shetty A, Alland D, Rodrigues C. Xpert MTB/RIF: a new pillar in diagnosis of extrapulmonary tuberculosis? Journal of clinical microbiology 2011;49(7):2540-45.

WHO. Treatment of tuberculosis: Guidelines for National Programmes.2003:11-25.

Samaila M O, Oluwole O P. Extrapulmonary tuberculosis: fine needle aspiration cytology diagnosis. Nigerian journal of clinical practice. 2011;14(3):297-99.

Ahmad A, Afghan S, Raykundalia C, Catty D. Diagnosis of tuberculosis by using enzyme-linked immunosorbent assay (ELISA) to detect anti-mycobacterial superoxide dismutase in the patients. $\mathrm{J}$ IslamcAcad of Sci.19987;11:1.

Global tuberculosis control:P key findings from the December 2009 WHO report. WklyEpidemiol Rec.2010;85(9):69-80.

World Health Organization (2011) Policy Statement: Commercial serodiagnostic tests for diagnosis of tuberculosis. WHO, Geneva, Switzerland. WHO/HTM/TB/2011.5. Available: http//www.who.int/tb/laboratory/policy statement/en.

Nakamura R M, Velmonte M A, Kawajiri K, Ang C F, Frias R A, Mendoza M T, et al., MPB64 mycobacterial antigen: a new skin-tet reagent through patch method for rapid diagnosis of active tuberculosis. The international journal of tuberculosis and lung disease: the official journal of the International Union against Tuberculosis and Lung Disease.1998:2(7):541-46. 
Pai M, Menzies D, Interferon-gam,ma release assays: what is their role in the diagnosis of active tuberculosis? Clin Infect Dis.2007;44(1):74-77.

Dewan P K, Grinsdale J, Kawamura L M. Low sensitivity of a whole-blood interferon-gamma release assay for detection of active tuberculosis. Clin Infect Dis.2007;44(1):69-73.

Vicenti D, Carara S, Butra O, Bizzoni F, Casetti R, Girardi E, et al., Response to region of difference $1(\mathrm{RD})$ epitopes in human immunodeficiency virus (HIV)infected individuals enrolled with suspected active tuberculosis: a pilot study. ClinExp Immunol.2007;150(1):91-987.

Brooks J B, Daneshvar M I, Fast D M, Good
R C. Selective procedures for detecting femtomoles quantities of tuberculostearic acid in serum and cerebrospinal fluid by frequencypulsed electron capture gas-liquid chromatography. Journal of clinical microbiology.1987;25(7):1201-06.

Galkin V B, lagafarova R K, Khokkanen V M, Grashchenkova O V. (Epidemiological and clinical aspects of extrapulmonary tuberculosis in North-Western Russia). Probl Tuberk.1998;36-38.

Wry is extra-pulmonary TB not a public health priority in India? Available at http:// www. Citizen-new. Org/2009/09/why-is-extra-pulmonarytb-not-public.html.

\section{How to cite this article:}

Ruckmani, K., A. Shanthi, P. Shanmugapriya and Eunice Swarna Jacob. 2021. Extra Pulmonary Tuberculosis in Body Fluids. Int.J.Curr.Microbiol.App.Sci. 10(07): 7-19. doi: https://doi.org/10.20546/ijcmas.2021.1007.002 